\title{
Designing a Public-Private Partnership Model for Public Hospitals in Iran
}

\author{
Mehdi Barzegar ${ }^{1}$, Seyed Jamaledin Tabibi ${ }^{*}$, Mohammad Reza Maleki², Amir \\ Ashkan Nasiripour ${ }^{1}$ \\ ${ }^{1}$ Department of Health Services Administration, Science and Research Branch, Islamic Azad University, Tehran, \\ Iran. ${ }^{2}$ School of Management and Medical Information, Iran University of Medical Sciences, Tehran, Iran.
}

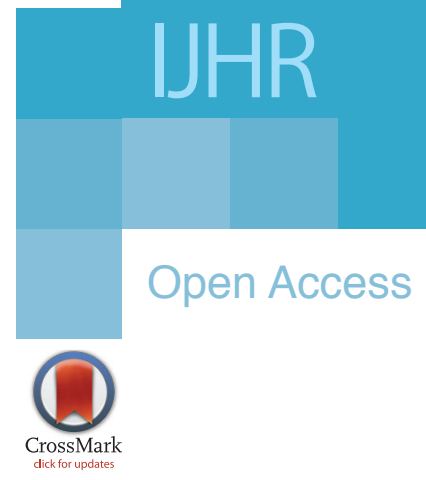

First Published online March 30, 2016

\begin{abstract}
Background and Objectives: Public-private partnership (PPP) is a well-established model to alleviate the risk of investment in health domain. While the model is widely applied in the developed countries, the adoption of the model in many developing countries is hampered partly by the lack of knowledge on dimensions and requirements of its local implementation. The present study, thus, aimed to identify the key aspects of PPP for hospital building in an Iranian context.

Methods: A comparative study of PPP implementation in seven pioneer countries revealed 53 elements potentially influencing development of PPP. Using rigorous expert opinion seeking, these elements were refined and adapted with respect to the Iranian context. Based on this information a 38-item questionnaire was designed. The questionnaire was distributed among 220 experts from different health domains, including clinicians of public and private hospitals and policy makers, executives, and authorized advisors from the Ministry of Health and Medical Education (MOHME) and various medical universities. The collected data were analyzed using exploratory factors analysis in order to identify factors influencing PPP development. The robustness of the identified factors was further explored by confirmatory factor analysis (CFA).
\end{abstract}

Findings: Legislation, policy making, finance, capacity building, and social orientation were identified as the five key dimensions of hospital-building PPP implementation in the Iranian context.

Conclusions: Identification of the major dimensions of hospital PPP implementation may help policy-makers to develop effective strategies for promotion of PPP in the Iranian health system.

Keywords: Public-private participation, Hospital management, Healthcare system

\section{Background and Objectives}

In many developing countries, the public sector has the major responsibility to develop the health system infrastructure, where the private sector plays a minor role due to factors such as high costs, long-run return on investment, weak financial power, and the lack of supportive laws and regulations. ${ }^{1,2}$ Factors such as advancement of medical sciences and technology, development of new therapies, lifestyle and socio-cultural changes, population growth, and the change in the nature of required health services, has imposed increasingly higher health expenditures to the health system of many countries, including Iran. ${ }^{3}$ Resent statistics has indicated that the expenditure of Iranian government on health accounts for over 15 of

${ }^{*}$ Corresponding Author: Seyed Jamaledin Tabibi Department of Health Services Administration, Science and Research Branch, Islamic Azad University, Tehran, Iran. Tel: +98 21 44865154, Email: tabibi@srbiau.ac.ir the total government expenditure, ${ }^{4}$ demonstrating the financial pressure for provision of health services. ${ }^{3}$

On the other hand the extensive bureaucracy in public sector induces many problems in the health sector. These include (among other factors) focused decision-making, poor management, poor inter-level communication, and low motivation for high efficiency. ${ }^{5}$

In Iran, while both public and private sector contribute to provide health services, the public sector is responsible for the majority of health system development expenditures. ${ }^{6}$ The lion share of health expenses in Iran is given to the hospitals. However, the situation of hospitals in terms of efficiency is not much satisfactory. ${ }^{7}$

Advantages associated with collaborative contribution of private and public sectors to provision of health services has embarked the policy-makers to devise bilateral solutions in which the interests of both sectors are met. A successful and extensively implemented model for such 
collaboration is the public-private partnership (PPP). ${ }^{8,9}$ PPP allows the public sector to use its strengths in order to promote justice and accessibility and at the same time take the advantages of skills and experience of private sector for higher efficiency and quality. ${ }^{10}$

PPP helps each partner achieve higher efficiency compared with the situation each sector operates alone. This partnership provides opportunity to overcome the financial challenge, enables more efficient management, and bridges the gap between infrastructural needs and available resources. ${ }^{11}$

Although a number of successful health PPPs has been launched and operated successfully in Iran, a comprehensive and coherent conceptual model for implementation of such partnerships is lacking. This lack contributes at least partially to the slow pace of supportive legislation and governmental support of health PPP development as well as obscurity of benefits from such partnership to the private sector. To contribute to filling this gap, this study was designed to develop a native model for PPP in the Iranian health context, based on the international experience and domestic constraints.

\section{Methods}

A comparative study of PPP implementation in seven pioneer countries, including Canada, England, Germany, Brazil, India, Thailand, and Lesotho was carried out using content analysis method. As a result, 53 elements potentially influencing development of PPP were identified. The published literature was further explored with respect to the identified elements resulting in formulation of a 53item questionnaire. The validity of the questionnaire was sought by expert opinion method (57 experts). As a result, 15 items were excluded and some other items were revised according to the expert advises. The resulting questionnaire comprised 38 items, scored on a 5-point Likerttype scale (from 1 = "very week" to 5 = "very strong"). The reliability of the questionnaire was ensured by Cronbach $\alpha$ of 0.85 .

The questionnaire was distributed among a sample of 220 individuals purposefully selected from among physicians and medical board members, policy makers, and experts from medical universities, the Ministry of Health and Medical Education (MOHME), hospital chief executive officers (CEOs).

The collected data was analyzed using exploratory factor analysis (EFA) to identify the factor structures underlying the data loadings across these factors. The sufficiency of sample size for factor analysis was ensured by Kaiser-Meyer-Olkin (KMO) score of 0.67. Bartlett test of sphericity resulted indicated the significance of the corre- lation matrix. Levene test showed that distribution of varii ances was homogeneous $(P>0.05)$. Principal component analysis was then performed with varimax rotation for factor extraction. The internal consistency reliability of the extracted factors was calculated using Cronbach $\alpha$. The models were then validated by confirmatory factor analysis (CFA). A series of goodness-of-fit indices including comparative fit index $(\mathrm{CFI})$, goodness-to-fit index (GFI), adjusted goodness-to-fit index (AGFI), and root mean squared error of approximation (RMSEA) were considered to evaluate the quality of model fit.

\section{Results and Discussion}

\section{Literature Review}

Table 1 summarizes the PPP-supporting efforts made by the pioneer countries in terms of legislation, policy-making, financing, capacity building and social orients. Among these efforts are distributed legislation in Canada, and development of supporting lows in Brazil, and policy-making aimed at protection of PPP in Lesotho. ${ }^{12-14}$

\section{Explanatory Factor Analysis and Model Improvement}

We preformed factor analysis with solutions with various number of factors. Ultimately, the 5 -factor solution turned out to be more consistent. Due to inadequate internal consistency of some extracted factors, a model improvement procedure was carried out. To develop more reliable model, an iterative cycle of model modification was run for each construct, and at each run, a single item that had low factor loading and communality was dropped from the model. Although the extracted factor in three methods was found to be almost identical, the varimax results which required less eliminated items, was chosen. The criteria for stopping the procedure were factor loadings of more than 0.3 for all items. The criteria were met for the constructs after removal of eight items from various factors. Table 2 shows the specific value, variance, and the cumulative variance of 5 factors. The specific values of all factors were higher than one. The identified factors together explain 66.52 of the total variance of the variables. Also internal consistency reliability of the 30 -item was calculated to be 0.71 . Reliability analysis of the factors in improved model identified adequate levels of internal consistency for all factors $(\alpha>0.7)$.

Based on their content, the factors were nominated as the following: Factor 1: Legislation, Factor 2: Policy-making, Factor 3: Financing, Factor 4: Capacity building, and Factor 5: Social orient. Table 3 presents the items of each factor and corresponding the factor loading.

The resulting model was validated by CFA. Results of fitness data analysis with single factor model (Table 4) 


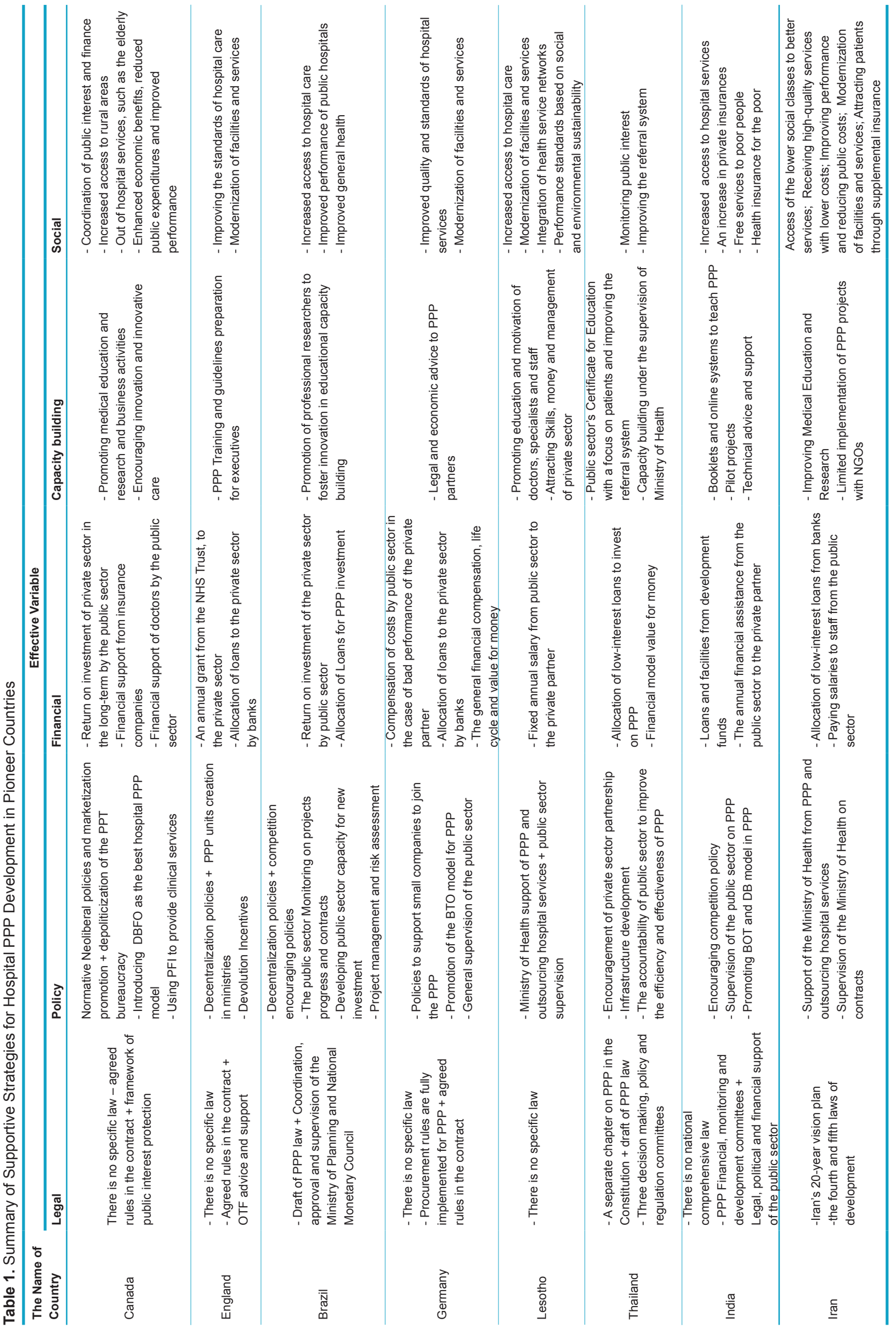


Table 2. Specific Value, Variance Percentage, and the Cumulative Variance Percentage of the Identified Factors

\begin{tabular}{llll}
\hline Factors & Specific Value & $\begin{array}{l}\text { Variance } \\
\text { Percentage }\end{array}$ & $\begin{array}{l}\text { 5 Factors Cumulative } \\
\text { Variance (\%). }\end{array}$ \\
\hline H & 6.422 & 21.407 & 21.407 \\
S & 3.953 & 13.178 & 34.585 \\
M & 3.792 & 12.640 & 47.224 \\
Z & 3.634 & 12.112 & 59.337 \\
E & 2.155 & 7.183 & 66.520 \\
\hline
\end{tabular}

shows that the single model is properly fitted with data which makes it explicit that the linear combination of 5-factor components in the questionnaire can build up the public and private partnership model for public hospitals in Iran.

Among items related to legislation, the "role of specific headquarters in supervising partnership plan" gained the highest factor loading. Consistently, Ghamami identified reliable legal and lawful structure for support of the private sector's interests as a prerequisite to successful implementation PPP. ${ }^{15}$

Among items related to policy-making, "focus of PPP policies on services quality" gained the highest factor loading. Quality of public services has also been highlighted in previous reports as an influential factor for promoting contribution of private sector to health services delivery. ${ }^{16}$

Among financial factors, "development of a relevant and standard financial management system" represented the highest factor loading. The same factor is reported to be crucial to development of PPP in the Brazilian health system. ${ }^{17}$

Among factors related to capacity building "training and empowerment of hospital employees" gained the highest factor load. According to the study of Jaafari, employee empowerment and improved managerial skills in public organizations are crucial to establish successful partnership between public and private sectors. ${ }^{18}$ Raman and Björkman in their study on PPP in India Health Sector identified the capacity building as an avenue to improved skills and competency in the health human resources, which in turn can help improve structures and processes essential for implementation of PPP. ${ }^{16}$

\section{Conclusions}

In this study, we developed a conceptual framework for the implementation of PPP in Iranian health facilities. Our

Table 3. Factor Loading for Items in Exploratory and Confirmatory Analysis

\begin{tabular}{|c|c|c|c|c|}
\hline $\begin{array}{l}\text { Main } \\
\text { Factors }\end{array}$ & Factors & Abbreviation & $\begin{array}{l}\text { Exploratory } \\
\text { Loading Factor }\end{array}$ & $\begin{array}{l}\text { Confirmatory } \\
\text { Loading Factor }\end{array}$ \\
\hline \multirow[t]{6}{*}{ Legislation } & Political decision based on consensus to develop public and private partnership & h1 & 0.53 & 0.77 \\
\hline & Developing legal infrastructures to facilitate partnership & h4 & 0.59 & 0.42 \\
\hline & Granting certification for healthcare public and private partnership & h5 & 0.61 & 0.24 \\
\hline & Establishing specified headquarter with a duty to update public and private partnership & h6 & 0.40 & 0.55 \\
\hline & Comprehensive supervision of partnership plans & h7 & 0.68 & 0.82 \\
\hline & $\begin{array}{l}\text { Clarifying the contract scope (size of the capital, risk-sharing mechanism, contract } \\
\text { duration, parties' commitments) }\end{array}$ & h8 & 0.49 & 0.11 \\
\hline \multirow{5}{*}{$\begin{array}{l}\text { Policy- } \\
\text { making }\end{array}$} & Reducing bureaucracy and preventive laws & s1 & 0.45 & 0.03 \\
\hline & Understanding and addressing PPP plans' problems & s2 & 0.32 & 0.14 \\
\hline & Focus of policies on the value of money in public and private partnership plan & s3 & 0.70 & 0.86 \\
\hline & Focus on services quality & s4 & 0.84 & 0.16 \\
\hline & Setting competence inspiring policies for PPP & s5 & 0.61 & 0.31 \\
\hline \multirow[t]{6}{*}{ Financial } & Setting clear financial goals & $\mathrm{m} 1$ & 0.35 & 0.80 \\
\hline & Specifying the situation of government financial aids & $\mathrm{m} 2$ & 0.34 & 0.81 \\
\hline & Promoting the partnership of insurance organizations & m3 & 0.78 & 0.52 \\
\hline & Specifying a clear mechanism for capital repayment of private sector & $\mathrm{m} 4$ & 0.52 & 0.69 \\
\hline & $\begin{array}{l}\text { Establishing a standard accounting and financial management system based on } \\
\text { financial model of the PPP plan }\end{array}$ & m5 & 0.80 & 0.49 \\
\hline & Dependence of finance in private sector to risk sharing and interest rate & $\mathrm{m} 7$ & 0.33 & 0.47 \\
\hline Capacity & Provision of training and research services by the participating hospitals & $\mathrm{z1}$ & 0.77 & 0.73 \\
\hline \multirow[t]{7}{*}{ Building } & Developing managerial instructions & z2 & 0.81 & 0.12 \\
\hline & Encouraging private sector to invest in PPP & z3 & 0.70 & 0.82 \\
\hline & Promoting research-based in health management & z4 & 0.77 & 0.47 \\
\hline & Education-based improvement of health care service management & $z 5$ & 0.53 & 0.58 \\
\hline & Training and empowering hospital employees & z6 & 0.74 & 0.95 \\
\hline & Improving quality of work life of the managers and employees & $z 7$ & 0.76 & 0.66 \\
\hline & Running pilot projects in order to gain better managerial insights & z8 & 0.35 & 0.49 \\
\hline \multirow[t]{5}{*}{ Social } & Attention to the public benefits and demands in partnership plan & e1 & 0.83 & 0.85 \\
\hline & Facilitating delivery of services to medium- and low-income families & e2 & 0.79 & 0.47 \\
\hline & Providing discount to individuals belonging to weak social and economic classes & e3 & 0.84 & 0.46 \\
\hline & Emphasize on satisfaction of patents and their visitors and visitors & e4 & 0.81 & 0.88 \\
\hline & Emphasize on environmental concerns & e5 & 0.81 & 0.81 \\
\hline
\end{tabular}


Table 4. Fitness Data Analysis for Single Factor Model

\begin{tabular}{lllllll} 
CFI & AGFI & GFI & RMSEA & P & df & 2 \\
\hline 0.799 & 0.732 & 0.842 & 0.022 & 0.001 & 398 & 5604.963
\end{tabular}

framework consists of five dimensions including Legislation, Policy-making, Finance, Capacity building, Social orients. We speculate that implementation of PPP with according to the requirements of these factors will result in alleviation of present inefficiencies in Iranian hospitals together with enhanced quality of care and patient satisfaction.

\section{Abbreviations}

(PPP): public-private partnership.

\section{Competing Interests}

The authors declare no competing interests.

\section{Authors' Contributions}

MB was involved in the study design, collecting and analyzing the data, and drafting the manuscript. SJT and MRM contributed to designing the study and revising the manuscript. AAN contributed to data analysis. All authors read and approved the final manuscript.

\section{Acknowledgements}

The authors are grateful to Dr. Etemadian, Dr. Shadpour, Dr. Soleimani and Dr. Shahhoseini who are the pioneers of hospital PPP in Iran for their useful discussions.

\section{Reference}

1. Bagheri M, Asgharnia M. Favorite legal structure for financing infrastructures. Proceedings of the national conference for public and private partnerships in infrastructure development; Supreme Education and Research Institute; 2012:125-134.

2. Groene, O, Garcia-Barbero M, Eds. Health promotion in hospitals: evidence and quality management. Copenhagen: WHO Regional Office for Europe; 2005.

3. Raghfar H, Zargari N, Sangari Mohazzab K. Measuring inequality in households' health care expenditures in Iran. Hakim Res J. 2013;16(2):89-97.

4. World Health Organization. Global health expenditure database. Geneva: WHO; 2013.

5. Walther M. Partnering capacity in with-collar public-private partnerships. Switzerland: Haupt Beme; 2010.

6. Shadpour P, Barzegar M, Afzal E. Study on the Impact of implementing public-private partnership (PPP) at Hasheminejad Kidney Center. Int J Hosp Res. 2013;2(4):195200.

7. Afsharkazemi M, Salarifar M, Nasiripour AA, Manouchehri J. Managerial factors affecting Tehran Heart Center performance: a study by fuzzy logic (Persian). Hospital J. 2012;10(27):1-9.

8. Eggers W. Closing the Infrastructure Gap: The Role of
Public-Private Partnerships. Deloitte. 2006. https://www2. deloitte.com/ie/en/pages/finance/articles/closing-theinfrastructure-gap.html.

9. Ebrahimi S, Abdi S. To identify risks in a variety of projects with emphasis on public-private partnership (Persian). Proceedings of the National Conference for Public and Private Partnerships in Infrastructure Development, Supreme Education and Research Institute; 2013:125-134.

10. Jabbari Beyrami $H$, Gholamzadeh Nikjoo R, Jannati $A$, Dadgar E. Introducing public-private partnership options in public hospitals (Persian). Hakim Res J. 2013;16(3):201210.

11. Narangoda B, Khathibi A. Public private partnership in healthcare industry in Sri Lanka as an alternative to privatization. Int J Manag Bus Res. 2014;4(2): 95-106.

12. Markey L. Identifying P3 Potential A Guide for Federal Departments \& Agencies,PPP Canada, 2012.

13. Fernandez RN, Carraro A, Menezes G, Neto GB. Design contract for public-private partnerships: a theoretical model for Brazilian hospitals. https://www.anpec.org.br/ encontro/2012/inscricao/files_1/i4-ab623262c542de76f3029 6090fb79f59.pdf. Published 2014.

14. World Bank. Lesotho New Hospital PPP Project, Report No: ICR2762. http://documents.worldbank.org/curated/ en/210731468263728217/Lesotho-New-Hospital-PublicPrivate-Partnership-PPP-Project. Published 2013.

15. Ghamami M. Public and private partnerships in infrastructure development Iran based on the principles in the Constitution and other laws (Persian). Proceedings of the National Conference for Public and Private Partnerships in Infrastructure Development; Supreme Education and Research Institute; 2013:741-775.

16. Raman AV, Björkman JW. Public/Private Partnership in Health Care Services in India. http://medind.nic.in/haa/t08/ i1/haat08i1p62.pdf. Published 2009.

17. Bettignies J, Ross TW. The economics of public private partnerships. Can Public Policy 2004;30(2):154-135.

18. Jaafari $\mathrm{D}$. The roll of public-private partnership in developing health section (Persian). Liman Magazine Consulting Architects \& Engineers. 2015;5:84-93.

\section{Please cite this article as:}

Barzegar M, Tabibi SJ, Maleki MR, Nasiripour AA. Designing a public-private partnership model for public hospitals in Iran. Int J Hosp Res. 2016;5(1):41-45. doi:10.15171/ijhr.2016.08. 